\title{
Aceptación de políticas de conservación ambiental: el caso de la Reserva de la Biosfera Mariposa Monarca
}

\section{Acceptance of environmental conservation policies: The case of the Monarch Butterfly Biosphere Reserve}

LUDGER BRENNER*

\begin{abstract}
This article analyses the reasons for the w eak results of several initiatives to promote the acceptance of environmental conservation public policies, based on the experience of the M onarch Butterfly Biosphere Reserve. We describe the problems faced by the management of this area and offer an analysis framework of the conflicts of the different parties interested in the natural resources. We then analyse the measures taken in order to stimulate the acceptance of environmental laws. Finally, we present an evaIuation of two different attempts to establish negotiation and coordination platforms.
\end{abstract}

Keywords: Conservation policies, negotiation platforms, monarch butterfly

\section{Resumen}

Este artículo analiza, con base en el ejemplo de la Reserva de las Biosfera $M$ ariposa $M$ onarca, las razones de los resultados de las iniciativas para promover la aceptación de políticas públicas de conservación ambiental. Se describen los problemas y se ofrece un marco de análisis de los conflictos entre los actores interesados en los recursos naturales. Finalmente se presenta la evaluación de dos intentos por establecer plataformas de coordinación y negociación.

Palabras clave: Políticas de conservación, plataformas de negociación, mariposa monarca

* Universidad Autónoma M etropolitana, Iztapalapa, M éxico. Correo-e: bren@xanum.uam.mx 


\section{Introducción ${ }^{1}$}

A partir los años setenta del siglo pasado, prevalecía la percepción de que los recursos naturales determinan y limitan el desarrollo humano. M ás tarde, el fuerte efecto del Informe Brundtland en 1987, de la Conferencia de Río en 1992 y de los diversos eventos subsiguientes, ponen en evidencia un mayor compromiso político de los Estados-naciones para tomar medidas que contrarresten el deterioro ambiental progresivo y conservar la biodiversidad. Aunque resulte cuestionable hasta qué punto se manifiestan en acciones eficaces, no cabe duda que se han intensificado los esfuerzos de promover una política de conservación, general mente segregativa, con el fin de controlar y restringir aquellas actividades humanas que ponen en peligro la biodiversidad del planeta. ${ }^{2}$ Lo cual se refleja -quizá de la manera más obviamediante la declaración de numerosas áreas naturales protegidas (ANP), en particular a partir de los años ochenta. Aunque las primeras An P se establecieron a finales del siglo XIX, sólo en los últimos treinta años se observa un incremento notable, tanto en el número total de AN P como en la extensión de la superficie terrestre y marina bajo algún tipo de protección legal. En este contexto, el concepto de las reservas de la biosfera (RB), promovido por la O rganización de las Naciones Unidas para la Educación, la Ciencia y la Cultura (un Esco), tiene un papel importante. ${ }^{3}$

A pesar de la consideración explícita de las necesidades de la población que reside dentro y en los alrededores de las ANP, su establecimiento implica una limitación del uso tradicional de los recursos naturales, justificada por la necesidad percibida de conservar el medio ambiente. En este contexto, el argumento de

${ }^{1} \mathrm{El}$ autor agradece el apoyo financiero y logístico brindado por el Instituto $\mathrm{N}$ acional de Ecología, la Dirección de la Reserva de la Biosfera M ariposa M onarca y el Word Wide Fund for $\mathrm{N}$ ature. Además, deseo expresar mi agradecimiento al maestro en geografía Sjoerd van der M eer (Universidad de Wageningen/Países Bajos), por su participación activa en la realización e interpretación de las entrevistas.

${ }^{2}$ www.iucn.org/themes/wcpa, consultado el 20 de marzo de 2008.

${ }^{3}$ El concepto de RB lo desarrolló la un Esco durante los setenta. Está estrechamente vinculado con el Programa $\mathrm{H}$ ombre y Biosfera y pretende fomentar el uso sustentable, activo y participativo de los recursos naturales. Para implementar este programa, hasta el día de hoy se han declarado unas 500 rв en más de 100 países. Aunque la declaración, el manejo y el financiamiento de RB sigue siendo responsabilidad de los Estados nacionales, la un EsCo ha elaborado una serie de lineamentos y criterios; además, se reserva el derecho de reconocer internacionalmente las RB declaradas por los Estados miembros. Actualmente M éxico cuenta con 38 RB (www.conanp.gob.mx, fecha de consulta: 7/11/ 2008), 34 de ellas reconocidas por la unEsco (www.unesco.org/mab/BRs, fecha de consulta: 7/11/2008). 
$\mathrm{H}$ ardin (1968), quien advierte que el uso comunitario no restringido de los recursos naturales conlleva inevitablemente a su deterioro progresivo, sirvió como justificación científica para conferir el control administrativo de tierras comunales en ANP a las instituciones gubernamentales (M erino y H ernández, 2004). En consecuencia, la administración de An p se ha realizado (y se sigue haciendo) con escasa participación de los afectados (Brenner y Job 2006). Sin embargo, una de las consecuencias de este tipo de política fue la resistencia de la población local y otros usuarios tradicionales contra las medidas administrativamente impuestas (Chapela y Barkin 1995). Al mismo tiempo, surgieron nuevos usuarios, por ejemplo, colonos inmigrantes, empresas dedicadas a la explotación de energéticos o el sector turismo (Bryant 1992); que también tienden a rechazar dichas medidas de conservación si van contra sus intereses. Por consiguiente, el uso comunal tradicional de los recursos se ha convertido en un nuevo régimen que podría llamarse, según Leeuwis y Van den Ban (2004), uso múltiple-público; lo cual implica una mayor complejidad de manejo.

Ya que las medidas de coerción resultaron difíciles de imponer y además ineficientes, las instituciones gubernamentales y las organizaciones no gubernamentales (oNG) buscaron medidas más blandas, con el afán de promover y flanquear la aceptación de An p por parte de la población local y los demás usuarios (Weizenegger, 2003). Generalmente consisten en programas de apoyo para crear fuentes alternativas de ingreso e impulsar ciertas actividades económicas no tradicionales, como el ecoturismo o la producción artesanal, entre otros, con la finalidad de compensar a los afectados por las restricciones (Barkin, 2000, 2003; Brenner 2006).

Sin embargo, el éxito de estas medidas resulta cuestionable. La degradación ambiental en muchas AN P mexicanas sigue avanzando (M elo, 2002; R amírez et al., 2003), y la resistencia contra la implementación de políticas ambientales no ha disminuido, pese a los apoyos considerables que se otorgaron a la población local (Brenner, 2004; M elo, 2002). En este contexto, aún no quedan suficientemente claras las razones por la escasa eficiencia de las medidas para promover una mayor aceptación de las Anp. Además, existen pocos trabajos que tratan de explicar de manera convincente la persistencia de los conflictos que suelen surgir entre los actores que pretenden imponer las medidas de conservación y los actores interesados en la explotación de los 
recursos naturales (Brenner y Job, 2006; Brenner et al., 2008). Aunque haya consenso con respecto a la creación de plataformas de negociación y coordinación (Grimble et al., 1995), resulta necesario conocer más a fondo los problemas subyacentes en los conflictos de intereses: si no hay certidumbre acerca de la naturaleza y complejidad de los conflictos entre los actores involucrados, el funcionamiento de dichas plataformas quedará en entredicho.

En este contexto, los complejos conflictos sociales relacionados con el establecimiento de la Reserva de la Biosfera $M$ ariposa M onarca (RBM M) (Chapela y Barkin, 1995; M erino y H ernández, 2004) constituyen un ejemplo que refleja los problemas en numerosas An p de M éxico y otros países de América Latina: se observa un deterioro ambiental progresivo, altos grados de marginación y enfrentamientos, a pesar de los múltiples programas y medidas para impulsar el desarrollo socioeconómico de la región, llevados a cabo por muchas instituciones gubernamentales y ong (Barkin, 2003; Brenner, 2006; Brenner y Job, 2006). Al mismo tiempo, se lanzaron iniciativas ambiciosas para establecer plataformas de diálogo y conciliación, con el afán de atender los problemas que han surgido en esta An P (Van der M eer, 2007).

Con base en lo expuesto, los objetivos centrales de este artículo son: a) presentar un marco conceptual para analizar debidamente los conflictos entre los actores interesados en el uso y conservación de los recursos naturales de la RBM m; b) analizar las medidas tomadas para fomentar la aceptación de la normatividad y regularización; y c) describir y evaluar los intentos de establecer plataformas de reconciliación y negociación.

A continuación se presentan brevemente los problemas que enfrenta el manejo de la RBM M. Enseguida se explican el acercamiento conceptual y la metodología puesta en práctica. Después se describen y analizan las medidas aplicadas por los diferentes actores para fomentar la aceptación de la normatividad de la reserva. También se evalúan los intentos de establecer plataformas de mediación de conflictos entre los actores involucrados. Finalmente se plantean al gunas propuestas para mejorar la eficacia de los programas de apoyo y la creación de nuevos espacios de negociación. 


\section{Conflictos y problemas de manejo de la Reserva de la Biosfera $M$ ariposa M onarca}

La RBM м (56,259 ha; zonas núcleo: 13,551 ha) fue declarada en 1986 y ampliada significativamente en 2000. Se encuentra en la región limítrofe del estado de M ichoacán y del Estado de M éxico (figura I) ${ }^{4}$ y es mundialmente conocida porque es la principal zona de invernada de la mariposa monarca (D anaus plexippus), una especie que se caracteriza por su conducta migratoria notable, científicamente comprobada apenas a finales de la década de 1970. La mariposa monarca pasa los meses de verano en varias regiones de Estados Unidos y del sur de Canadá. A principios del otoño la población entera de mariposas inicia su migración hacia del sur, debido al descenso de temperatura y la disminución de insolación para pasar los meses del invierno (noviembre a marzo) en la zona boscosa de la reserva (para más detalles véase $\mathrm{H}$ oth et al., 1999). A mediados-finales de marzo la población inicia su regreso. En este ciclo migratorio anual participan varias generaciones de mariposas (para más detalles véase H oth et al., 1999; Conanp, 2001; Galindo et al., 2004; Galindo y Rendón, 2005). Debido al fenómeno de migración que abarca gran parte de América del Norte, la mariposa monarca se ha convertido en un símbolo de integración del subcontinente; lo que obliga al gobierno mexicano a tomar medidas para conservar su hábitat invernal (Brenner y Job, 2006).

C abe resaltar, sin embargo, que otra función crucial de la RBM M y sus zonas cercanas es el suministro de agua para las áreas metropolitanas de la ciudad de M éxico y Toluca. D ebido a las altas precipitaciones, las condiciones edafológicas y la cobertura forestal aún considerable, la región tiene una alta capacidad de retención de agua (M erino et al., 1995); razón por la cual una parte notable del agua consumida en los valles de M éxico y Toluca se extrae de las mantos freáticos de la RBM m y sus zonas aledañas, mediante el sistema acuífero Cutzamala. ${ }^{5}$ En este sentido, la necesidad políti-

${ }^{4}$ Según la Ley General del Equilibrio Ecológico y la Protección al Ambiente (Art. 47 bis), las zonas núcleo de las RB tienen como "objetivo principal la preservación de los ecosistemas y sus elementos, de investigación y de colecta científica, educación ambiental, y limitarse o prohibirse aprovechamientos que alteran los ecosistemas". En cambio, las zonas de amortiguamiento tienen "como función principal orientar a que las actividades de aprovechamiento, que ahí se llevan a cabo, se conduzcan hacia el desarrollo sustentable, creando al mismo tiempo las condiciones necesarias para lograr la conservación de los ecosistemas".

${ }^{5}$ Se trata de un volumen de unos 13,300 litros por segundo en 2007 (EI Financiero, 21 de septiembre de 2007, p. 33). 


\section{Figura I}

\section{Reserva de la Biosfera de la M ariposa M onarca:}

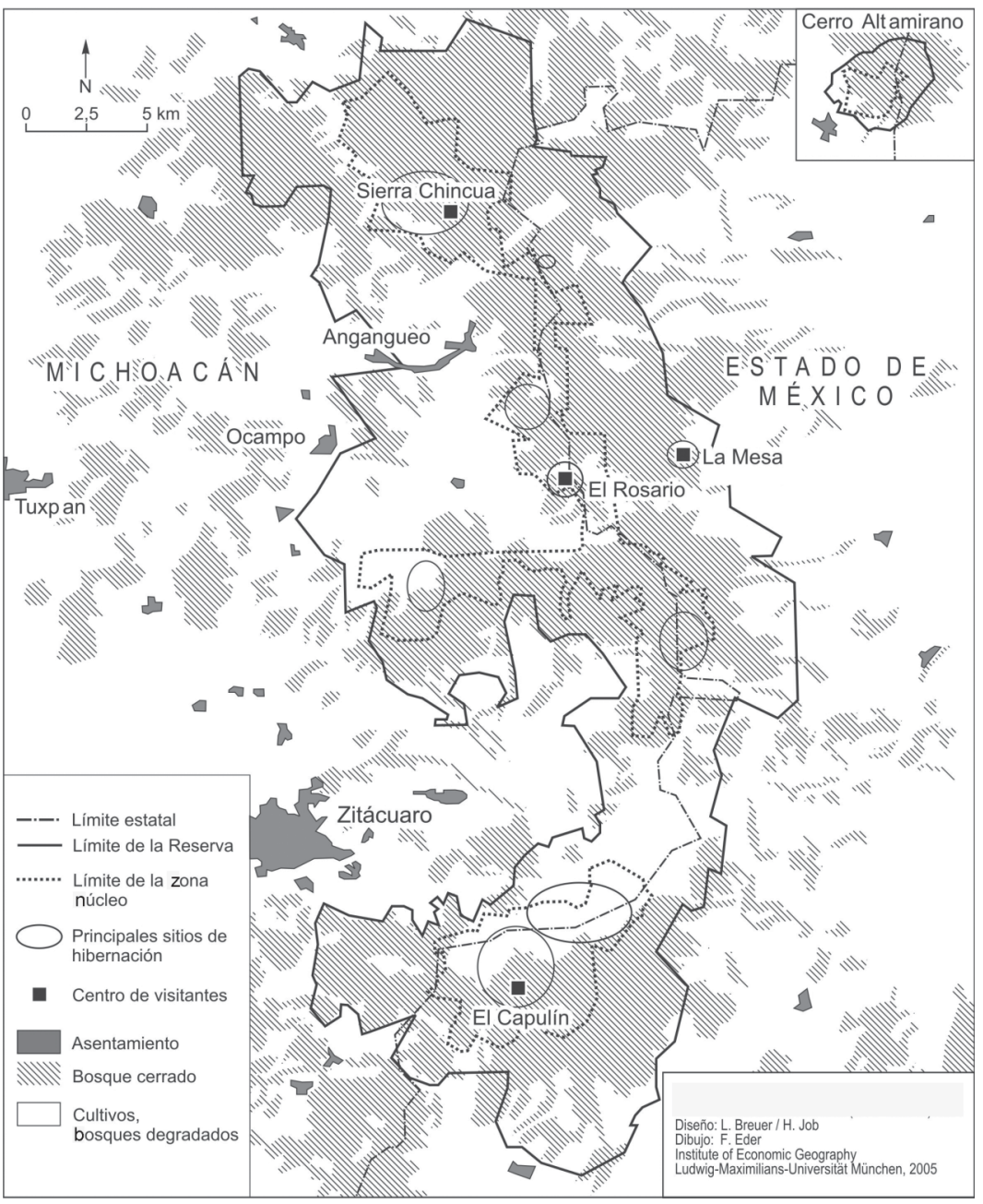

Fuente: C. Galindo Leal, J. H oney Roses y A. I. M artínez Pacheco (ww F M éxico), 2004. 
ca de conservar el funcionamiento de estos servicios ambientales, estrechamente vinculados con la extensión de la cobertura forestal, se puede considerar un motivo crucial de las intensas actividades que realiza una amplia gama de instituciones gubernamentales; por tanto, el sistema acuífero Cutzamala es hoy de gran importancia política en esta zona. En consecuencia, no sería improcedente afirmar que la conservación del suministro de agua -en términos políticos- resulta más importante que la de una especie de lepidópteros, que ni siquiera está en peligro es extinción. ${ }^{6}$

Cabe destacar que la RBM m es una de las An P más pobladas de M éxico; cuenta con unos 100,000 habitantes dentro de sus límites (Van der M eer, 2007). La población, mestiza e indígena principalmente, se dedicaba a la agricultura de subsistencia (cultivo de maíz y cría de ganado menor, en escala más pequeña al cultivo de hortalizas y fruticultura) en los valles aluviales más fértiles (Conanp, 2001). Por razones edafológicas, orográficas y heladas frecuentes, el rendimiento es bajo, pese al mayor uso de tractores, fertilizantes y productos fitosanitarios. Aunando a eso, la región es una de las más marginadas del centro-occidente mexicano, ya que no se establecieron empresas industriales de mayor importancia y el sector terciario básicamente se limita al comercio (Conapo, 2000; M erino et al., 1995; M artín, 2001). Además, la situación de la tenencia de la tierra se presenta sumamente compleja. Domina el régimen ejidal (sobre todo población mestiza) y comunitario (en su mayoría población indígena), aunque también existen predios en manos de pequeños propietarios y de instituciones federales: en total, la reserva está integrada por 59 ejidos, 13 comunidades indígenas y 21 pequeñas propiedades (Galindo y Rendón, 2005) con diferentes historias locales y estructuras sociales.

La explotación forestal, hasta los años cincuenta, limitada principalmente al uso doméstico local (madera de construcción, leña, producción de artículos de uso corriente), ${ }^{7}$ hoy tiene un papel importante en la economía regional (M artín, 2001; WWF, 2004). El incremento de población, la falta de fuentes de ingre-

${ }^{6}$ Cabe mencionar que el hábitat de la mariposa monarca fuera de América del $\mathrm{N}$ orte es extenso y actualmente no se considera una especie amenazada en el mundo (Galindo y Rendón, 2005).

${ }^{7}$ Debido a la altitud de 2,200 a 3,800 metros sobre el nivel del mar, la relativa infertilidad de los suelos (tipo andosol de origen volcánico que se caracteriza por la fijación de los fosfatos naturales) y la mala comunicación vial, los extensos bosques (especies dominantes: Pinus sp. y Quercus sp., en las partes más altas Abies religiosa) fueron explotados extensivamente y permanecieron en gran parte intactos hasta los años cincuenta (Galindo y Rendón, 2005; Ramírez et al., 2003). 
sos y la demanda creciente de muebles, madera para la construcción y celulosa en las zonas urbanas cercanas a la ciudad de M éxico, Toluca y M orelia tuvo como consecuencia una intensificación de la explotación de los bosques y una extensión de la superficie bajo cultivo, sobre todo en declives ásperos; lo que causó una degradación ecológica progresiva (Brenner y J ob, 2006; Brower et al., 2002; Chapela y Barkin, 1995; M erino y H ernández, 2004; WWF, 2004). La misma no se refleja tanto por desmontes en gran escala, sino más bien mediante una aclaración paulatina de los bosques antaño densos, con consecuencias severas para los ecosistemas locales (figura I; Ramírez et al., 2003; Brower et al., 2002). Por ejemplo, Brower et al. (2002) estiman que entre 1971 y 1999, 44\% de los bosques conservados (en 1971) se convirtieron en bosques degradados, aunque en diferentes niveles. ${ }^{8}$

Básicamente existen dos formas de explotación forestal, ahora ilegales o restringidas: la primera, en general conocida como tala hormiga, se refiere a la extracción limitada de madera para el uso doméstico tradicional de la población residente. Aunque a menudo se realiza ilegalmente, los ejidos y comunidades también disponen de licencias que les permiten extraer cierta cantidad de madera. ${ }^{9}$ Se considera que el impacto ambiental que causa es menor, ya que en general se usa la madera seca o muerta y se talan relativamente pocos árboles vivos. En cambio, la tala masiva tiene un efecto más severo debido al mayor volumen y las prácticas de extracción (M erino et al., 1995; M erino y H ernández, 2004). Esa forma de explotación y transformación de maderas es controlada por grupos de talamontes organizados y bien equipados, cuyos miembros se reclutan de la población regional, así como comerciantes y fabricantes de muebles foráneos con sede en Zitácuaro, Ciudad H idalgo, Toluca y otros lugares de la región. Es común que se practique durante la noche y se talan cantidades notables de árboles vivos comerciables. Los troncos se venden inmediatamente después a aserraderos y comerciantes de maderas con sede en Ciudad $\mathrm{H}$ idalgo, $\mathrm{O}$ campo, Z itácuaro, Angangueo, San José del Rincón e incluso Toluca (M artín, 2001; H arner, 2002; WWF, 2004). Vale la pena mencionar que la

${ }^{8}$ Sin embargo, todavía sigue en disputa la importancia de la cobertura forestal para la conservación de la población de la mariposa monarca. Como argumentan algunos investigadores (H oth et al., 1999; Rendón et al. 1997), una densidad menor de cobertura forestal permite un mejor crecimiento de plantas importantes para la alimentación de las mariposas durante el periodo de hibernación.

${ }^{9}$ Sólo se permite extraer ciertas cuotas precisamente establecidas en la zona de amortiguamiento; queda estrictamente prohibida en la zona núcleo (Conanp, 2001). 
participación en la tala masiva es tentadora, debido al riesgo relativamente bajo y las ganancias altas en comparación con otras fuentes de ingreso ( $M$ artín, 2001). Pese la presencia de diferentes cuerpos policiacos, ${ }^{10}$ las medidas de control de la tala masiva resultaron poco eficientes, ${ }^{11}$ sobre todo en la porción michoacana de la reserva (figura I; Ramírez et al., 2003; wWF, 2004). Vale la pena mencionar que la intensidad de participación en la tala masiva en buena medida depende de las condiciones socioculturales locales: mientras en algunos ejidos, comunidades y pequeñas propiedades se presenta una explotación excesiva de los recursos forestales que beneficia a ciertos actores particulares, en otros casos, se ha asegurado un manejo forestal sustentable y bajo control comunal (Cohan, 2007; M artín, 2001; wwF, 2004). En este contexto, los factores cruciales son la historia local, el grado de homogeneidad social de las comunidades y las coaliciones de intereses específicas entre las élites locales y los actores forasteros (Garibay y Bocco, 2000; M artín, 2001). Así, resulta crucial la capacidad de las comunidades individuales para llevar a cabo actividades de vigilancia efectivas, que eviten la intrusión de los grupos organizados de talamontes (Tucker, 2004).

Cabe destacar que, desde un principio, la explotación forestal ha sido el principal punto de conflicto entre las autoridades gubernamentales y la población local. Un problema crucial fue la declaración de la reserva en 1986 sin previa consulta con los habitantes; y relacionado con ella, la limitación repentina de la explotación legal de los bosques (Chapela y Barkin, 1995). Con el fin de disminuir la presión sobre los recursos naturales, y en particular para frenar la tala masiva, el gobierno federal y los gobiernos de los estados de M ichoacán y M éxico, así como varias ONG, iniciaron numerosos programas de fomento para generar fuentes alternativas de ingresos (Barkin, 2003; Brenner y J ob, 2006; Conanp, 2001). No obstante, muchos estudios ponen en duda el éxito de dichas iniciativas (por ejemplo, M artín, 2001; Barkin, 2003; Brenner y Job, 2006; Chapela y Barkin, 1995; M erino et al., 1995; Van der M eer, 2007; wwF, 2004). Además,

${ }^{10}$ Se trata sobre todo de los cuerpos policiacos municipales y estatales, pero también intervienen varias instituciones federales (Profepa, PGR, entre otros), encargadas de imponer la reglamentación legal de la explotación forestal.

${ }^{11}$ La intervención de las instituciones gubernamentales en el aprovechamiento forestal en la RBM m se remonta a los años cincuenta, cuando se impusieron vedas durante periodos prolongados en los estados de Michoacán y M éxico. No obstante, estas medidas no han tenido el efecto deseado: no resultó viable controlar la extracción de madera comerciable y para uso doméstico. M ás bien se dio origen al arraigo de tala clandestina en toda la región (M artín, 2001; M erino y H ernández, 2004). 
la aparición de nuevos usuarios, como el sector turismo (Barkin, 2000; Brenner, 2006; Cohan, 2007), y la intensificación de usos tradicionales, como la extracción de agua potable (Conanp, 2001), aumenta la presión sobre la masa forestal. Por consiguiente, no cabe duda que los recursos naturales de la RBM m actualmente están en disputa entre numerosos actores, interesados en diferentes tipos de uso.

\section{A cercamiento conceptual}

En términos teórico-conceptuales, los procesos sociopolíticos en la RBM M y otras AN P mexicanas, durante las últimas décadas, se pueden interpretar como una conversión sucesiva de los recursos naturales de uso tradicional-comunal, en recursos de uso múltiple-público (M aarleveld y Dangbégnon, 1999; Steins y Edwards, 1997). ${ }^{12}$ El primer régimen se caracteriza por una relativa homogeneidad social de usuarios y un tipo de uso específico de recursos naturales. Típicamente se trata de diferentes modalidades de propiedades comunales, donde el acceso a y el control sobre los recursos naturales se rige según ciertas reglas, que pueden ser relativamente flexibles en términos institucionales o bien más formales, con normas legalmente establecidas. Sin embargo, en general se trata de una mezcla entre ambas formas de arreglos del acceso y control. En todos los casos existen amplias extensiones de tierras de uso común, frecuentemente bosques, manejadas bajo un régimen comunal. Los derechos de usufructo se limitan a un número definido de usuarios y a ciertos usos determinados, por ejemplo, la extracción de madera o recolección de plantas.

En cambio, un régimen de uso múltiple-público surge cuando aparecen usuarios ajenos de las comunidades locales, con intereses más heterogéneos y potencialmente conflictivos. Con la presencia de más actores, la intensidad del aprovechamiento de los recursos natural es tiende a incrementarse (Bryant y Bailey 1997). En este contexto, ciertos usos tradicionales se pueden intensificar, o bien se inicia el aprovechamiento de otros recursos, antaño no explotados (Blaikie, 1999).

Una de las consecuencias del aumento de usuarios y de la intensificación del uso de los recursos naturales es la aparición de

12 En este contexto, el "no-uso", es decir, la prohibición o limitación de usos económico de recursos, también se puede considerar una forma de uso (para usos estéticos/uso opcional para el futuro, etcétera). 
conflictos y la agudización de disputas. Estos conflictos surgen de los intereses, estrategias y acciones contrapuestos y difícilmente compatibles, que persiguen los actores respectivos (Brenner y Job, 2006; Blaikie, 1995, 1999). En este contexto, un acercamiento político-ecológico con enfoque en los actores sociales se presta como marco de análisis, puesto que se refiere explícitamente a conflictos ambientales que resultan del acceso a y uso de los recursos naturales (Bryant y Bailey, 1997; Bryant, 1992, 1997; Blaikie, 1999). ${ }^{13}$ Las investigaciones político-ecológicas coinciden que actores pueden ser individuos o grupos sociales colectivos, según Lambin et al. (1999), todos los individuos, hogares y empresas que actúan conforme a sus propios cálculos y reglas de decisión, se deben considerar como actores. O tros autores (Bryant, 1992, 1997; Bryant y Bailey, 1997), sin embargo, argumentan que instituciones gubernamentales, oNG y comunidades locales también son actores importantes, aunque generalmente no constituyen unidades homogéneas en términos sociales. Esta situación conlleva una mayor complejidad del manejo de recursos en general y de las AN p en particular. Además, en muchas ocasiones surgen situaciones conflictivas a raíz de los intereses contrapuestos y difícilmente compatibles.

En este sentido, la declaración de una An P con frecuencia afecta arreglos y formas de uso y de manejo preexistentes; lo cual genera una situación potencialmente conflictiva. No sorprende, por tanto, que los actores que inducen confrontaciones, es decir, las instituciones gubernamentales, pronto se ven obligadas a gestionar aquellos conflictos, con el afán de resolverlos con el menor costo político. De manera que se convierten nolens volens en mediadores de conflictos, pero al mismo tiempo siguen siendo actores con intereses y estrategias claramente definidos. En este contexto, la percepción que los actores gubernamentales y de algunas ONG influyentes, tienen de sus propias funciones, representa un problema serio. Por lo general proceden de la siguiente manera: a) decidir lo que es necesario; b) anunciar la decisión y comunicar las medidas por implementar; y c) defender estas medidas y buscar apoyo político para ellas (Leeuwis y Van den Ban, 2004). Lo cual implica una visión instrumental de política: la solución de un problema social, como el manejo adecuado de

${ }^{13}$ Se reconoce que existen otros acercamientos y conceptos para analizar conflictos sociales (por ejemplo, Brenna 2006; Tischler y Carnero 2001). No obstante, se optó por un acercamiento analítico político-ecológico por su referencia explícita a conflictos medioambientales. 
una ANP, se considera responsabilidad exclusiva y preponderante de uno o varios actores particulares, que intentan lograr ciertos objetivos apoyándose en una gama de instrumentos a su alcance (medidas legales, incentivos, retórica, entre otros) (Goodhand y H ulme, 1999). Un ejemplo sería la política tradicional de administración de ANP, donde las instituciones gubernamentales tratan de impedir la explotación de recursos naturales, recurriendo a facultades legales y medidas de coerción, pero también a estímulos económicos en beneficio de la población afectada. Según esta percepción, el resto de la sociedad se considera un conjunto de actores influenciables. En el caso señalado, el objetivo último no sería una participación efectiva de la población local, sino más bien la aceptación de recursos económicos a cambio del cese de ciertas actividades económicas, consideradas (por las autoridades gubernamentales) no compatibles con la protección ambiental. En consecuencia, lo que se busca no es la participación durante la fase de la toma de decisión, sino en primer lugar la aplicación eficaz de ciertas medidas predefinidas. En este sentido, el problema no necesariamente es la decisión política en sí -que puede ser compartida por los demás actores-, sino la aceptación de decisiones operativas ya tomadas (Van Woerkum, 1997). N o sorprende, por tanto, que muchas comunidades estén dispuestas - por lo menos en términos generales- a contribuir a la protección ambiental; pero no aceptan las medidas concretas propuestas por las autoridades (Barkin, 2003).

Vale la pena destacar que aceptación de decisiones puede tener diferentes significados (Leeuwis y Van den Ban, 2004; Van Woerkum, 1997): por un lado, se puede referir al motivo de las políticas. En este caso, los actores pueden coincidir o no con respecto a la pertinencia y/o gravedad del problema subyacente. Lo cual es menos probable en el ámbito de la política ambiental, ya que la gran mayoría de los actores secundan el objetivo de la conservación de los recursos naturales, por lo menos en términos generales. Por otra parte, aceptación se puede relacionar con la legitimidad de la intervención de ciertos actores determinados, es decir, la legitimidad percibida por un conjunto de actores para que un actor particular intervenga para resolver ciertos problemas. En este sentido, algunos actores no rechazan el motivo político en sí, sino la legitimación de que un actor externo intervenga en asuntos percibidos como exclusivamente locales. Cabe mencionar que este tipo de rechazo es más frecuente: es común observar una profunda desconfianza de las comunidades locales 
frente a las instituciones gubernamentales (Cohan, 2007; Chapela y Barkin, 1995). Finalmente, aceptación puede remitirse a la eficacia y la legitimidad de las acciones por tomar, o bien al consenso entre los actores involucrados de que una medida concreta sería la más eficiente y justa. También constituye un asunto conflictivo en el contexto del manejo de ANP, puesto que muchas acciones tienden a controlar y restringir los derechos de disposición y usufructos de los recursos naturales (Bryant 1992; M erino y Hernández, 2004).

Una posible solución para atender los conflictos y promover la aceptación de políticas de conservación y sus medidas es el establecimiento de una plataforma multiactor, ${ }^{14}$ que se puede definir, según Röling, como "a negotiation body (voluntary or statutory), compromising different stakeholders who percieve the same resource management problem, realise their interdependences in solving it, and come together to agree on action strategies for solving the problem" (1994, citado en Steins y Edwards, 1997: 17). Como indica esta definición, el funcionamiento de una plataforma multiactor requiere cumplir una serie de precondiciones: por un lado, debe existir cierto consenso en cuanto a la necesidad que resolver de manera conjunta una problema urgente que corresponde a todos los actores involucrados. En este contexto, es importante que los actores perciban y acepten una dependencia mutua y estén dispuestos a dialogar. Por otra parte, las decisiones tomadas deben comprometer a los actores, es decir, tienen que ser más que declaraciones no obligatorias. En este sentido, para establecer exitosamente una plataforma multiactor es necesario tomar en cuenta los siguientes aspectos:

- El nivel espacial donde se establece la plataforma y su alcance depende del tipo del problema por resolver, es decir, de las características de los recursos naturales en disputa y de los actores interesados en ellos. Aunque la relevancia territorial del problema es relativamente fácil de definir (por ejemplo, la explotación de agua en una cuenca o la explotación forestal en una ANP), hay que tomar en consideración que los actores se manejan en diferentes niveles espaciales (internacional, nacional, regional y local). Algunos de ellos, como las instituciones del gobierno central, están en condiciones de actuar en diferentes niveles al mismo tiempo (Brenner y H üttl, en prensa).

${ }^{14}$ En inglés se usa el término multi-stakeholder platforms. 
- Las facultades de la plataforma también están relacionadas con el tipo de problema a resolver. Sin embargo, la plataforma debe disponer de facultades de decisión que permitan ejecutar acciones concretas e independientes de la benevolencia de otros actores no participantes. En este sentido, las decisiones que toman los integrantes de la plataforma no deben ser anuladas por un actor ajeno (Brenner y Job 2006).

- Además, es crucial la inclusión y representación de gran parte de los actores afectados, involucrados e interesados. Todos los actores relevantes deben ser representados adecuadamente; lo cual resulta problemático en el caso de actores colectivos, como las comunidades locales. Además, es necesario contar con una amplia disposición por parte de estos: el derecho formal no garantiza que todos realmente quieran o puedan participar. Pueden existir obstáculos como distancia física y falta de experiencia en los procesos administrativos que impiden la toma de decisiones más democrática (Weizenegger 2003).

- Finalmente, hace falta un mediador aceptado: la plataforma debe ser dirigida y gestionada por un mediador neutro y ampliamente respetado. Este hecho facilitaría la posibilidad de llegar a acuerdos pragmáticos en un tiempo razonable y aseguraría la continuidad de la plataforma, además de que reduciría los costos de transacción (Van der M eer, 2007).

\section{Iniciativas para promover la aceptación de políticas públicas}

Para identificar y caracterizar a los actores que participan en la implementación de políticas públicas y los problemas percibidos con respecto a su aceptación por parte de la población afecta$\mathrm{da},{ }^{15}$ se aplicaron varios métodos cualitativos: por un lado, se realizaron, grabaron y transcribieron un total de 45 entrevistas semiestructuradas durante el periodo de septiembre de 2004 a febrero de 2005. Estas entrevistas se hicieron a 16 representan-

${ }^{15} \mathrm{EI}$ autor quiere destacar que no se pretende evaluar cuantitativamente los resultados concretos o la eficacia real de cada una de las medidas tomadas por los diferentes actores. Aunque sin duda es interesante y necesario, un propósito de esta envergadura rebasaría los límites de este trabajo. Se reconoce el éxito parcial de algunas actividades, por ejemplo, las acciones realizadas por el World Wide Fund for Nature (véase más adelante). Sin embargo, un número considerable de publicaciones con enfoque biológico-ambientalista (wwF, 2004; Ramírez et al., 2003, entre otros) comprueba claramente que no se ha logrado frenar el deterioro ambiental en la zona. Por tanto, es obvio que las medidas de conservación en su conjunto no han sido eficaces. 
tes de instituciones del gobierno federal, seis del gobierno de M ichoacán y cinco a representantes del gobierno del Estado de M éxico. Además, se entrevistó a ocho funcionarios de los ayuntamientos municipales afectados por la declaración del la RBM M, así como 10 colaboradores de oN G. La razón para el gran número de entrevistas radica, en buena medida, en la división política de la reserva que se ubica en dos entidades federativas: en varias ocasiones estaban involucrados en la misma área administrativa (por ejemplo, la supervisión de la explotación forestal) tres dependencias federales y estatales. Al mismo tiempo, la fama internacional de la RBM m y del fenómeno biológico de la migración de la mariposa monarca atraen el interés de numerosas ONG de diferentes tipos.

Sólo se hicieron entrevistas con instituciones gubernamentales y ong con un interés particular en el uso y/o la conservación de los recursos natural es de la reserva; que disponían de programas o proyectos propios para influenciar directa o indirectamente las modalidades del uso de los recursos naturales. Vale la pena mencionar que todas las medidas analizadas tienen como propósito la conservación ambiental; aunque algunos también persiguen otros objetivos adicionales. Sin embargo, también las acciones realizadas para mejorar la infraestructura y las condiciones socioeconómicas de la población residente, pretenden coadyuvar a disminuir la presión sobre los recursos forestales. Para seleccionar las instituciones por entrevistar, se recurrió al sistema de bola de nieve, es decir, primero a los representantes de instituciones directamente involucrados en la administración de la reserva, así como a las on G más conocidas que operan en la región. Con base en estas entrevistas y observaciones durante los recorridos en la zona, se identificaron sucesivamente otros actores, que fueron entrevistados después. Para completar la información proporcionada por las organizaciones formalmente establecidas, se realizaron 11 entrevistas con diferentes informantes clave provenientes de los ejidos y comunidades indígenas. Con el interés de seleccionar estas comunidades de manera sistemática, se tomaron en consideración los siguientes criterios: tipo de comunidad (ejidos o comunidad indígena), su ubicación en las entidades federativas (M ichoacán o Estado de M éxico) y las zonas de la Rвм м (zona núcleo o de amortiguamiento); así como la presencia o ausencia de colonias de mariposa monarca. A parte de la realización y trascripción de las entrevistas, se recopiló información adicional mediante la participación en varias reuniones ofi- 
ciales que tuvieron los grupos de actores, por ejemplo, asambleas ejidales y reuniones del Consejo Asesor de la Reserva de la Biosfera M ariposa M onarca.

Como se muestra en la figura $I,{ }^{16}$ son muchas las instituciones y organizaciones; además estaban implementando una gran variedad de programas $^{17}$ con la finalidad de promover la aceptación de la reserva por parte de la población local. En esta figura también se señala que había diferencias considerables no sólo en cuanto al enfoque sectorial, sino también con respecto a las modalidades y reglas de operación, así como a los recursos financieros que tienen a su disposición los actores respectivos. En lo que concierne a las modalidades de operación, se pueden distinguir programas relativamente rígidos con una limitada flexibilidad operativa, comúnmente gestionados por instituciones federales que disponen de recursos considerables. Por otra parte, las instituciones estatales y las on $\mathrm{G}$ es frecuente que se caractericen por una mayor flexibilidad administrativa. Sin embargo, generalmente no tienen igual acceso a recursos financieros. Cabe destacar que también hay excepciones, por ejemplo, las instituciones estatales que reciben transferencias por parte del gobierno federal, 0 bien el World Wide Fund for $\mathrm{N}$ ature (WWF) que, al ser una prestigiosa ONG internacional, está en condiciones de movilizar recursos notables.

A grandes rasgos se pueden distinguir tres grupos de actores con intereses y objetivos diferentes, aunque a menudo coinciden en cuanto a sus estrategias y medidas concretas: por un lado, se identificaron instituciones gubernamentales que tratan de implementar programas para estimular el desarrollo económico regional, mediante la generación de fuentes de ingreso alternativas a la explotación forestal tradicional, apoyo a la modernización y diversificación de producción, construcción de infraestructura,

\footnotetext{
${ }^{16}$ Esta figura sintetiza gráficamente las características más sobresalientes de los programas y tiene una función hermenéutica y exploratoria. Al tratarse de un enfoque cualitativo, los ejes no representan valores numéricos, sino el criterio de los gradientes respectivos se refieren a la flexibilidad operativa, es decir, la capacidad de adoptar las medidas concretas a las condiciones locales; y al acceso actual y/o potencial a fuentes de financiamiento. Para posicionar las instituciones y sus actividades, se revisaron cuidadosamente tanto los enfoques y las reglas de operación de los programas, así como, en algunos casos, los montos aplicados o disponibles. Además, se compararon los documentos oficiales (proporcionados por los entrevistados y obtenidos de las páginas web institucionales) con las transcripciones de las entrevistas, con el afán de contrastar ambas fuentes de información.

${ }^{17} \mathrm{M}$ e refiero a los programas vigentes y en operación durante del periodo de trabajo de campo.
} 


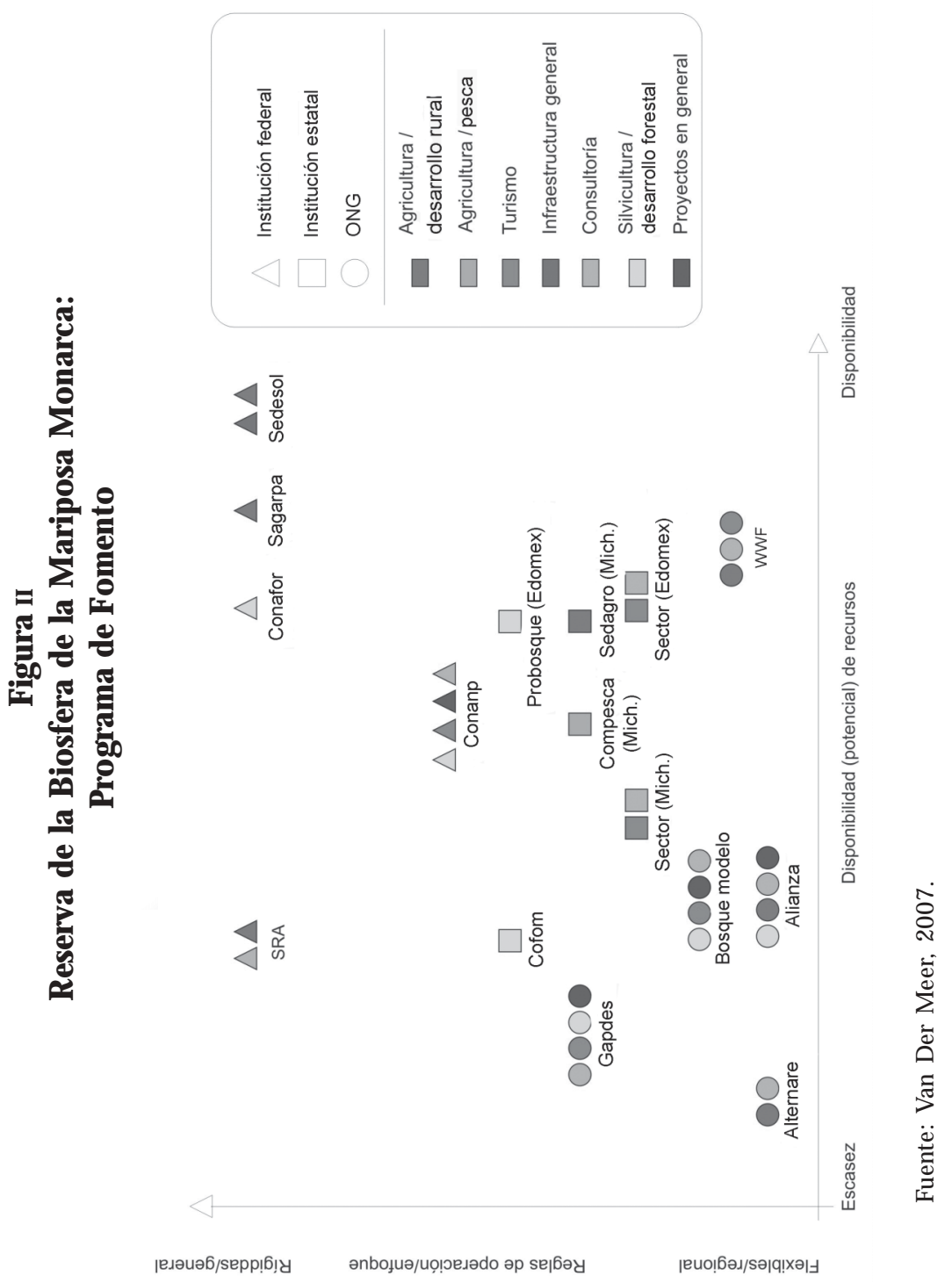


así como asesoría en general con el objetivo de disminuir la presión sobre los recursos forestales. A este grupo de actores pertenecen la Secretaría de Desarrollo Social (Sedesol), la Secretaría de Agricultura, Ganadería, Desarrollo Rural, Pesca y Alimentación (Sagarpa), la Secretaría de la R eforma Agraria (SRA), las secretarías de Turismo de M ichoacán y del Estado de M éxico (Sectur), la Secretaría de D esarrollo Agrícola (Sedagro) y la Comisión de Pesca (Compesca), las últimas dependencias del estado de M ichoacán (figura ॥). Vale la pena mencionar de manera ejemplar algunos de los programas que llevan a cabo las instituciones mencionadas: las delegaciones regionales de la Sedesol en M ichoacán y el Estado de M éxico gestionan, entre otras cosas, el Programa de Empleo Temporal enfocado a rehabilitar y mejorar la infraestructura social y productiva en zonas rurales marginadas, ofreciendo trabajo temporal a la mano de obra sub o desempleada. La Sagarpa es responsable de llevar a cabo los programas Apoyo al Campo y Alianza para el Campo. Ambos pretenden mejorar las estructuras productivas en zonas rurales y brindan subsidios para la producción agrícola y ganadera. Todos estos programas se aplican en gran parte del territorio nacional, sin distinguir entre áreas protegidas y no protegidas. Sin embargo, al tratarse de An p federales, las medidas concretas se deben coordinar con las dependencias de la Secretaría del M edio Ambiente y Recursos $\mathrm{N}$ aturales (Semarnat), principalmente con su órgano descentralizado, la Comisión N acional de Áreas N aturales Protegidas (Conanp).

O tro grupo de actores incluye a las instituciones gubernamentales encargadas de la protección ambiental y/o del control administrativo del aprovechamiento de los recursos naturales, en este caso de los forestales, aunque también gestionan una serie de programas para estimular el desarrollo local y regional. Cabe mencionar, en primer lugar, a la Conanp que tiene a su cargo, por medio de la dirección de la Rвм M, la tarea de controlar la normatividad del uso de suelo y, relacionado con ello, las actividades económicas que se desarrollan en el territorio de la reserva. Además, esta dirección es responsable de la coordinación interinstitucional, cuya finalidad es evitar redundancias en cuanto a las actividades que realizan las demás instituciones de los tres niveles de gobierno, así como atender -en primera instancia- las demandas sociales de las comunidades locales residentes. Al mismo tiempo, apoya diferentes actividades productivas en el ámbito de la silvicultura y el turismo, entre otras, administrando re- 
cursos proporcionados por otras dependencias federales (figura II). Aparte recibe recursos financieros provenientes del Banco $M$ undial mediante el Fondo G lobal Ambiental y del Fondo M exicano para la Conservación de la Naturaleza; este último financiado por una serie de instituciones públicas y on G. Son importantes también las tres instituciones encargadas del control y supervisión de la explotación forestal, así como del apoyo a ciertas actividades ecológicamente sustentables relacionadas con la silvicultura: Ia Comisión N acional Forestal (Conafor), la Comisión Forestal del Estado de M ichoacán (Cofom) y la Protectora de Bosques del Estado de M éxico (Probosque). La Conafor, mediante el Programa de Desarrollo Forestal, el Programa para el Desarrollo de Plantaciones Comerciales y el Programa de Conservación y Restauración de Ecosistemas Forestales brinda apoyo financiero y consultaría a comunidades y pequeños propietarios para elaborar planes de manejo forestal, establecimiento de plantaciones y reforestación, entre otros. Cofom y Probosque llevan a cabo actividades similares en su entidad respectiva, en ocasiones administrando directamente los programas en representación de la Conafor. Cabe destacar que Probosque cuenta con más recursos financieros y humanos que Cofom (figura॥).

Por último, las on internacionales y locales también desarroIlan una amplia gama de actividades en la reserva, enfocadas a promover la conservación de los recursos naturales y crear fuentes de ingresos alternativas. Por tanto, coinciden a grandes rasgos con los objetivos de las instituciones gubernamentales antes mencionadas y con frecuencia recurren a recursos públicos para financiar sus actividades. No cabe duda que la más influyente de ellas es el wwF (Programa M éxico); que se dedica primordialmente a la gestión del Fondo para la Conservación de la M ariposa M onarca, apoyado por donaciones de la Fundación Packard, la Semarnat, así como por los gobiernos de los estados de M ichoacán y de M éxico. Los recursos de este fondo se destinan a compensar a los ejidos y comunidades indígenas por actividades de conservación y el no aprovechamiento de sus bosques, es decir, se realiza un pago anual que corresponde con el tamaño de la cobertura forestal de cada comunidad, siempre y cuando la masa forestal no se disminuya ni se deteriore. Vale la pena destacar que la mayoría de las comunidades afectadas por el decreto recibe dicha compensación, aunque siguen las disputas sobre el monto insuficiente de los pagos y el método de evaluación de los cambios de la cobertura vegetal. El wwF también destina recursos para impulsar el turismo 
y para elaborar planes de manejo forestal. Por otra parte, la ONG internacional Bosque $\mathrm{M}$ odelo $\mathrm{M}$ ariposa $\mathrm{M}$ onarca fomenta diversos proyectos comunitarios en diferentes ejidos y comunidades indígenas para mejorar la infraestructura turística, impulsar la cría de truchas y la producción de artesanía y de alimentos orgánicos, así como la silvicultura sustentable. Para estas actividades también recibe apoyo financiero y logístico de una serie de instituciones gubernamentales, como la Sedesol, la Conafor, Probosque, la Cofom, Segem y Sectur. Actividades similares realiza la on G local Alternare, aunque su margen de maniobra financiera es más limitado: depende, en buena medida, de los recursos otorgados por los ayuntamientos locales (figura ॥). En cambio, las dos organizaciones restantes -Alianza de los Ejidos y Comunidades de la Reserva de la Biosfera M ariposa M onarca (Alianza) y G estión Ambiental y Programa para el Desarrollo Sustentable (Gapdes)- no realizan proyectos propios, más bien solicitan y gestionan una serie de programas gubernamentales, a petición de las comunidades locales no familiarizadas con los procedimientos burocráticos. Por tanto, se pueden considerar como instituciones consultoras, aunque no tengan esta figura jurídica. Ambas organizaciones retienen un porcentaje de los recursos públicos otorgados para cubrir sus gastos de operación. Al ser una organización influyente y con aspiraciones de intervenir directamente en la política del manejo de la reserva, Alianza ha sido capaz de obtener recursos considerables.

Después de describir la amplia gama de actores involucrados y programas aplicados, surgen por lo menos dos preguntas: ¿han servido todas estas actividades para promover la aceptación de la RBM M ? y ¿se ha logrado una mejor conservación de los recursos naturales? En vista del deterioro continuo de los bosques de la reserva, nos inclinamos a responder que no. No obstante, las razones de la degradación de la masa forestal y de los suelos son complejas; y el análisis de sus causas no debería reducirse a la evaluación de programas institucionales. Sin embargo, vale la pena analizar más a fondo los obstáculos que están afectando su eficacia.

Con base en las entrevistas realizadas, se pueden identificar los siguientes problemas: a) existe un gran número de programas, pero insuficientemente coordinados; b) las características y diseño de los programas gubernamentales general mente no toman en cuenta las condiciones socioeconómicas locales; c) las actividades se concentran en un número reducido de comunidades y sectores sociales; y d) los programas no toman en consideración los intereses y el poder de los actores ajenos a las comuni- 
dades locales, capaces de explotar los recursos forestales en contra de la voluntad de la población residente y las autoridades gubernamentales.

La mayoría de los entrevistados opina que el problema central es la falta de coordinación de los programas; lo cual no sólo causa confusión entre los beneficiarios potenciales, sino también redundancias. En este sentido, el problema no radica tanto en la presencia de muchos actores y programas, sino más bien en la implementación al azar. El hecho de que las tres entidades involucradas (el Poder Ejecutivo Federal y los estados de M ichoacán y de M éxico) están gobernadas por tres partidos políticos diferentes, complica aún más la coordinación y cooperación intergubernamental:

$\mathrm{H}$ an intervenido bastantes organizaciones sociales que confunden, en lugar de orientar, a las poblaciones de la región. Y también veo que la mayoría [... ] busca el provecho hacia el interior de su organización y no trata de resolver la problemática de la reserva [... ]. Tampoco ayuda mucho que la Federación, el Estado de M éxico y M ichoacán tienen gobiernos de tres partidos diferentes" (entrevista con la Delegación Regional de Conafor en el estado de M ichoacán, 25 de octubre de 2004).

Aparte de eso, algunos entrevistados destacaron los conflictos de competencia entre las diferentes instituciones gubernamentales:

No hay un proyecto de desarrollo [coordinado por] las diferentes dependencias federales o del gobierno estatal, no hay una coordinación. Entonces, el gobierno local ofrece sus programas, el gobierno estatal los suyos [...] y el gobierno federal hace lo mismo [...]. Eso ocasiona mucho conflicto en la región y estancamiento (entrevista con Alternare, 28 de enero de 2005).

El problema también [... ] es que cada quien baja sus recursos, pero aisladamente. $\mathrm{N}$ o hay un proyecto integral y [... ] los resultados no son de mucho impacto (entrevista con la Delegación Regional de Sedesol en el estado de M ichoacán, 25 de octubre de 2004).

En aras de crear mecanismos de coordinación, varios entrevistados señalaron la necesidad de un plan de desarrollo regional para evitar el fomento de ciertas actividades económicas en zonas no apropiadas, por la fragilidad del ecosistema u otros factores. Al mismo tiempo, se insistió en que hace falta concentrar los esfuerzos en las comunidades y zonas que más lo necesitan, así como evitar redundancias como consecuencia de las acciones poco coordinadas. En este contexto, algunos funcionarios públi- 
cos y colaboradores de on $\mathrm{G}$ destacaron que no sólo falta un plan de desarrollo obligatorio para todos los actores involucrados, sino también una institución líder con las competencias para implementarlo. En teoría, esta tarea corresponde a la dirección de la RBM M, pero no se considera un actor suficientemente influyente para resolver los problemas estructurales:

A mí me parece que la [dirección de la] Reserva de la Biosfera M ariposa M onarca debería de tener un plan, un programa [... ], que fuera ella la que dirigiera, ordenara y diseñara [... l lo que se tiene que hacer (entrevista con Compesca, 26 de octubre de 2004).

$\mathrm{N} o$ hay alguien que encabece un ordenamiento de las actividades que se pueden desarrollar en la reserva (entrevista con Alternare, 24 de enero de 2005).

O tro punto que destacaron los entrevistados se refiere a la planeación e implementación centralizada de la mayoría de los programas, que con frecuencia no corresponden con la realidad social de la mayoría de las comunidades. En particular, fueron criticadas las iniciativas que realizan las instituciones federales $y$, en menor medida, las autoridades estatales; mismas que fueron diseñadas para todo el territorio nacional o bien para entidades federativas de gran extensión y diversidad socioeconómica.

Además, los requisitos administrativos rígidos para liberar y gestionar los recursos generan un obstáculo, en ocasiones insuperable para las comunidades locales. También se consideró problemático que la gran mayoría de los programas no tiene un efecto estructural, ya que están enfocados a proyectos de corto plazo, de acuerdo con la lógica y los periodos presupuestales. En el mismo orden de ideas, hubo entrevistados que opinaron que las instituciones deciden de manera autoritaria lo que necesitan las comunidades, sin consulta previa ni conocimiento preciso de la situación local: "En la reserva no hay una planeación de fondo. Se planea desde el escritorio, se imaginan cosas que no son la realidad de la gente [... ]. Todos los programas son bajo reglas de operación federal, que todo tiene que ver con todo el país y que no están de acuerdo con la realidad de la reserva" (entrevista con Alternare, 24 de enero de 2005).

Aparte de eso, para varios informantes resultó preocupante la marcada concentración de acciones y recursos en unos cuantos ejidos (como El Rosario, en el estado de M ichoacán) y comunidades indígenas, cuyos líderes tienen cierta experiencia en el ámbito político-administrativo. Algunos entrevistados incluso 
mencionaron que existen comunidades que pueden subsistir sólo con base en los recursos públicos asignados:

[El gobierno] siempre está dando recursos, subsidiando al campo, nada más por dar. Es un rollo de clientelismo, de partidismo [... ]. En El Rosario, el año pasado les estaban dando recursos, proyectos y demás, y la gente rechazó proyectos porque decían que ya no los necesitaban. Se ha acostumbrado a la gente a recibir dinero sin hacer nada (entrevista con WWF, 4 de noviembre de 2004).

En este contexto, parece que es un factor decisivo la existencia de colonias de mariposa monarca; lo cual permite a ciertos ejidos y comunidades indígenas favorecidas ejercer presión sobre las instituciones gubernamentales y on G. Vale la pena añadir que las mismas estructuras de organización social locales impiden una distribución más equitativa de los beneficios económicos otorgados. En particular, la situación jurídica ejidal tiene como consecuencia que sólo los ejidatarios acreditados y sus familias reciban apoyo financiero, hecho que margina a gran parte de los residentes sin derechos agrarios (Cohan, 2007). Otra deficiencia radica en el hecho de que los programas están dirigidos a comunidades ubicadas en la RBM M , ignorando la influencia real de otros actores que explotan los recursos naturales. "Lógicamente, los actores que impiden mucho [...] son precisamente los de la industria forestal" (entrevista con SUM A, 10 de noviembre de 2004).

En este contexto, se enfatizó que las actividades no toman en consideración a los grupos organizados de talamontes, responsables en gran parte del deterioro de la masa forestal.

En resumen, en el caso de la RBM m se observa una visión instrumental de la política ambiental por parte de la mayoría de los actores, en particular de las instituciones gubernamentales, pero también, aunque en menor medida, de varias on que perciben el deterioro de la masa forestal y la amenaza que enfrentan los sitios de hibernación de la mariposa monarca como problemas por resolver con los instrumentos que tienen a su disposición. Frente a la poca eficiencia de medidas coercitivas para imponer normas legales en un territorio difícilmente gobernable, to do indica que se dio preferencia a la canalización de recursos financieros hacia comunidades locales, consideradas actores importantes para la conservación de los recursos forestales, cruciales no sólo para conservar una especie emblemática, sino también para el suministro de agua para gran parte de los valles de M éxico y de Toluca. A final de cuentas, la asignación de fondos tiene 
la finalidad de convencer a la población local de que finalmente acepten la conversión de los recursos naturales de uso tradicional-comunal en recursos de uso múltiple-público bajo la gestión de una serie de autoridades gubernamentales. En este contexto, vale la pena mencionar que -quizás con la excepción de actores más independientes como el wwF o Bosque Modelo- las ONG coadyuvan de manera indirecta a implementar este tipo de política ambiental, puesto que dependen de la gestión y aplicación de programas gubernamentales para su subsistencia.

En este sentido, el problema radica no tanto en aceptar la necesidad de proteger los recursos forestales por parte de las comunidades locales, ni en la legitimidad de la intervención de instituciones gubernamentales en sí, sino principalmente en la baja eficacia y la poca credibilidad de las medidas concretas. $\mathrm{H}$ asta la fecha no hay consenso entre la amplia gama de actores (instituciones gubernamentales, oNG y comunidades locales) con respecto a la manera de definir, coordinar y aplicar medidas comúnmente consideradas como eficientes y justas. Hecho que posiblemente afectaría, por lo menos a mediano plazo, la credibilidad y el margen de maniobra de las instituciones gubernamentales y de las ONG.

\section{Plataformas multiactores}

Vale la pena mencionar que durante la última década se ha intentado implementar acciones de coordinación intragubernamental, tanto en los estados (Programa Integral de la Región M ariposa M onarca, en el Estado de M éxico y la Coordinación de Relaciones Interinstitucionales, en M ichoacán) como en el ámbito federal (Plan de O rdenamiento Ecológico de la Región M ariposa M onarca" ${ }^{18}$ en la actualidad en proceso de aprobación legal). Aunque seguramente sería interesante evaluar los resultados de aquellos esfuerzos, en lo fundamental se trata de instrumentos que buscan mejorar la eficacia de las acciones llevadas a cabo por diferentes

${ }^{18}$ El O rdenamiento Ecológico constituye "un instrumento de la política ambiental mexicana que está instituido por la Ley General del Equilibrio Ecológico y la Protección al Ambiente desde 1988 [... ] para maximizar el consenso y minimizar el conflicto en la sociedad" (Semarnat, 2006, V-VI). Es, por tanto, un instrumento de plantación territorial para lograr sucesivamente una mayor compatibilidad del uso de suelo y de las actividades económicas que se llevan a cabo en una zona determinada con los principios del desarrollo sustentable. El Programa de Ordenamiento Ecológico de la Región M ariposa M onarca abarca no menos de 27 municipios, 16 en M ichoacán y 11 en el Estado de M éxico (www.semarnat.gob.mx/ consultado en abril de 2008), es decir, un área considerablemente más amplia que la misma rвm . 
instituciones gubernamentales, así como reducir las redundancias y evitar el desarrollo de actividades potencialmente dañinas en zonas ecológicamente frágiles. Sin embargo, no se pueden considerar espacios de negociación para mitigar los conflictos de intereses, puesto que su finalidad principal no consiste en involucrar actores ajenos al sector gubernamental.

Por consiguiente, a continuación se describen y analizan las dos plataformas establecidas hasta la fecha: el Foro Regional de la M ariposa M onarca (FRM M) y el Consejo Asesor de la Reserva de la Biosfera M ariposa M onarca (CA), considerados por la mayoría de los entrevistados como los espacios de negociación más prometedores. Por un lado, se llevó a cabo el primer frmm en marzo de 2004, organizado por la Semarnat (Conanp), los gobiernos del Estado de M éxico y de M ichoacán, así como el wwF y la Universidad N acional Autónoma de M éxico (UNAM) (cuadro 1). H asta la fecha se han realizado cuatro foros, es decir, uno cada año. Uno de los motivos principales para convocar el FRM M fue la preocupación por la degradación continua de los recursos naturales, el efecto limitado de los programas realizados y la ausencia de una estrategia concertada para impulsar la conservación ambiental y el desarrollo socioeconómico regional (Van der $M$ eer, 2007). Por consiguiente, el objetivo principal del fRM m fue la formulación sucesiva de una estrategia para analizar y atender, de manera conjunta y coordinada, los complejos problemas de la RBM m y sus al rededores (Rendón et al., 2005). En este sentido, el desideratum ha sido la creación de un foro para una planificación regional intersectorial y eficaz, con la participación de una amplia gama de actores sociales (cuadro 1). N o cabe duda que la iniciativa encontró resonancia, ante todo, en el ámbito político-administrativo: en el primer foro regional participaron un total de 334 representantes de los tres niveles del gobierno, oNG, empresas, así como un número reducido de miembros de ejidos y comunidades indígenas (Van der M eer, 2007). La asistencia aumentó aún más en los eventos subsiguientes. Generalmente se discuten las diferentes problemáticas que enfrenta el manejo en varias mesas de trabajo (Rendón et al., 2005).

Según la percepción de varios entrevistados, el logro principal de los foros fue reunir por primera vez a representantes de una amplia gama de sectores sociales para discutir los problemas que enfrenta la reserva: "El Foro Regional $\mathrm{M}$ ariposa $\mathrm{M}$ onarca fue un logro muy importante. Se juntan todos los actores que existen [... ] para tratar diferentes temas, que son la cuestión del 
diagnóstico, la cuestión de la investigación, de educación, de difusión [... ]. El Foro fue un gran triunfo" (entrevista con Segem, 1 de noviembre de 2004).

En este contexto, es importante resaltar que fue durante estos eventos cuando se presentaron los avances del Programa de Ordenamiento Ecológico de la Región M ariposa M onarca y de otras iniciativas de planificación regional, desarrolladas por ambos gobiernos estatales; lo que indica que los foros anuales ejercen cierta presión política sobre las instituciones públicas para desarrollar instrumentos de coordinación. Además, como destacaron varios entrevistados, el hecho de que los integrantes de las mesas de trabajo se reúnan también de manera más o menos regular antes y después de los foros anuales, indica que hay cierto avance con respecto al análisis de problemas y la búsqueda de soluciones: "El Foro puede servir también como catalizador para que todo el mundo se entere de la problemática y que se pueda atenderla de manera más inmediata" (entrevista Conanp, 4 de noviembre de 2004).

Sin embargo, aún no se ha logrado convertir el FRM m en una organización con la facultad de tomar decisiones que comprometan a los participantes para actuar de conformidad con los acuerdos establecidos, ya que carece, a fin de cuentas, de medidas para imponer los compromisos contraídos de manera informal: "El intento de ponernos de acuerdo está bien, aunque creo que no se logró el objetivo todavía. Creo que se tiene que tratar de que sean menos acuerdos, pero más sustanciosos [... ], que sean firmados [... ] con compromisos por las máximas autoridades, porque de nada sirve que lo firme cualquier persona si no tiene el respaldo de los gobernadores, por ejemplo" (entrevista Profepa, 16 de noviembre de 2004).

De esta manera, se destacó que los ejidos y comunidades indígenas, en general, no consideran al foro como un órgano con poderes superiores a los de las instituciones locales, por ejemplo, las asambleas ejidales. Por otra parte, a pesar de los esfuerzos de los organizadores para evitar esta impresión, el grueso de la población local sigue relacionando el FRM M con el sector gubernamental, tradicionalmente considerado un conjunto de actores poco confiables y desinteresados en la solución de problemas local es. ${ }^{19} \mathrm{~N}$ o sorprende, por tanto, que muchos entrevistados

\footnotetext{
${ }^{19}$ Resultado de las entrevistas realizadas en los ejidos Contepec, Pueblo N uevo Solís, San Juan Palo Seco y Chincua, así como en la comunidad indígena Donaciano Ojeda (enero de 2005).
} 
opinaran que la ausencia y falta de participación activa de las comunidades locales son obstáculos cruciales para convertir el FRM M de una mesa de discusión a un órgano de conciliación y toma de decisiones. De manera que el problema principal no radica en el alcance espacial (regional) de esta plataforma potencial, sino más bien en sus facultades limitadas, así como en las expectativas y objetivos divergentes de los actores involucrados. $M$ ientras predominan las instituciones gubernamentales y las o N G, la gran mayoría de la población que reside en la RBM m y sus alrededores prefiere buscar otras formas de perseguir sus intereses. Además, por la ambigüedad de los acuerdos sin compromiso real, su heterogeneidad y división interna, así como por la ausencia de una persona líder carismática, resulta difícil que se perciba el FRM M como una plataforma de negociación por parte de la población residente.

\section{Cuadro 1 \\ C aracterísticas de las plataformas en la Reserva de la Biosfera $M$ ariposa M onarca}

\begin{tabular}{|c|c|c|}
\hline & $\begin{array}{l}\text { Foro Regional de la } \\
\text { Mariposa Monarca }\end{array}$ & Consejo Asesor de la RBмm \\
\hline Estatus legal & Voluntario & Legalmente establecido \\
\hline Promotores & Semarnat, gobiernos estatales, & $\begin{array}{l}\text { Gobierno federal (Conanp) } \\
\text { WWF, UNAM }\end{array}$ \\
\hline $\begin{array}{l}\text { Responsables de } \\
\text { organización }\end{array}$ & $\begin{array}{l}\text { Coordinadores de mesas } \\
\text { de trabajo provenientes de } \\
\text { diferentes organizaciones } \\
\text { gubernamentales }\end{array}$ & Conanp (Dirección de la RBM M) \\
\hline $\begin{array}{l}\text { Frecuencia de } \\
\text { reuniones }\end{array}$ & $\begin{array}{l}\text { Anual (mesas de trabajo dos } \\
\text { o tres veces al año) }\end{array}$ & $\begin{array}{l}\text { Variable, pero en general } \\
\text { varias veces al año }\end{array}$ \\
\hline $\begin{array}{l}\text { Procedencia de los } \\
\text { participantes }\end{array}$ & $\begin{array}{l}\text { Internacional, nacional, } \\
\text { regional, local }\end{array}$ & Local y regional \\
\hline Representación & $\begin{array}{l}\text { Organizaciones y comunidades } \\
\text { individuales (sin cuotas } \\
\text { sectoriales) }\end{array}$ & $\begin{array}{l}\text { Por sectores (municipios, } \\
\text { academia, onG, Conanp, } \\
\text { comunidades; cuotas fijas } \\
\text { por sector) }\end{array}$ \\
\hline $\begin{array}{l}\text { Participación de la } \\
\text { población local }\end{array}$ & $\begin{array}{l}\text { Limitada, poca participación } \\
\text { en discusiones }\end{array}$ & $\begin{array}{l}\text { Notable; participación activa } \\
\text { en discusiones }\end{array}$ \\
\hline O bjetivos y enfoque & $\begin{array}{l}\text { Coordinación, evitar } \\
\text { redundancias, planificación } \\
\text { regional }\end{array}$ & $\begin{array}{l}\text { Participación directa en el } \\
\text { manejo de la RBм M, aprobación } \\
\text { el Programa O perativo Anual }\end{array}$ \\
\hline Alcance & Región $M$ ariposa $M$ onarca & RBM M (27 municipios) \\
\hline
\end{tabular}

Fuente: Entrevistas propias; Rendón et al., 2005; Van der M eer, 2007. 
Por otra parte, el Consejo Asesor (CA) es un organismo establecido por la Ley General de Equilibrio Ecológico y la Protección al Ambiente (cuadro 1). Sus funciones básicas constituyen la asesoría de las direcciones de las An P respectivas y la aprobación de los Programas 0 perativos A nuales. Puesto que estos programas establecen el monto del presupuesto y los rubros previstos, el ca se puede considerar un parlamento en el nivel de las AN P mexicanas. Sin embargo, no participa en la elaboración de los programas ni en el ejercicio de los recursos financieros aprobados (esto corresponde a las direcciones). Con el afán de promover una participación de la sociedad civil, el ca está integrado de manera proporcional por representantes de Conanp, de las comunidades locales, de los ayuntamientos municipales, on y de instituciones académicas. En el caso de la RBMm, el consejo se creó en 2003 y (durante la realización del presente estudio) estuvo integrado por representantes electos de varios ejidos y comunidades indígenas, municipios que conforman la RBM M (Zitácuaro y Villa de Allende), del wwF, Alternare y Bosque M odelo, así como de la Universidad M ichoacana de San N icolás de H idalgo. Aunque el ca está encabezado por un presidente ejecutivo (un representante de alguna comunidad local) y un secretario técnico (un funcionario de la Conanp), la mayoría de las reuniones se realizan en varios subconsejos y comités microrregionales, de acuerdo con los asuntos a tratar. Esta división tiene la finalidad de representar mejor a las comunidades y atender problemas específicos.

No obstante, las entrevistas y las observaciones durante el trabajo de campo ${ }^{20}$ permitieron detectar una serie de problemas que, en conjunto, merman notablemente las facultades reales del CA. Pese a la participación e interés de las comunidades locales, la heterogeneidad social, las diferencias internas, el interés en el propio provecho y la falta de espíritu de solidaridad hacen que las sesiones se lleven a cabo de manera caótica y raramente conducen a resultados concretos. Por ejemplo, se observó la costumbre de pasar por alto el orden del día para presentar de manera espontánea asuntos particulares. Además, las discusiones las dominan unos cuantos individuos influyentes, familiarizados con la retórica política. En consecuencia, a menudo no se toman decisiones concretas, sino se opta por establecer otro comité que analice los problemas detectados (Van der M eer, 2007). Tam-

${ }^{20}$ Se asistió a varias reuniones de los subconsejos del CA. 
bién resulta problemática la ausencia frecuente de los representantes acreditados, en combinación con la intervención de personas ajenas en el proceso de toma de decisiones (ibid.). Además, la falta de experiencia e interés en asuntos administrativos tiene como consecuencia una aprobación por default del Programa O perativo Anual, elaborado por la Dirección de la RBm m: "N os presentan un Programa O perativo Anual ya elaborado, ya no más para que lo aprobemos [... ] y eso [... ] no es el objetivo del consejo [... ]; hay consejeros que dicen 'está bien así' porque no saben la realidad de las cosas [... ] o porque son amigos del director" (entrevista Alianza, 24 de enero de 2005).

En este sentido, la heterogeneidad social del CA -explícitamente intencionada por parte de los legisladores federales y la Conanp- tiene como consecuencia su escasa eficacia. La falta de legitimidad de los representantes ejidales afecta aún más el funcionamiento del CA: a raíz de la organización social tradicional de los ejidos, sólo un ejidatario puede ser consejero; así que los demás habitantes carentes de derechos agrarios se quedan sin voz ni voto: "Yo creo que tiene que estar más involucrada la gente [... ]. Q ue no solamente haya un representante [... ]. Cuando se va a tomar una decisión importante, pues se tiene que discutir ampliamente" (entrevista Alternare, 28 de enero de 2005).

Además, el hecho de que el ca no tiene competencias fuera del territorio de reserva afecta aún más su peso en el ámbito político; lo cual se muestra ante todo en el caso de combate a la tala masiva ejecutada por actores externos. En este sentido, el alcance del cA no corresponde con el nivel espacial donde se origina el problema.

\section{Conclusiones y recomendaciones}

El análisis político-ecológico con enfoque en actores, intereses y conflictos se presta, más que una evaluación cuantitativa del deterioro ambiental, a detectar los obstáculos sociopolíticos que enfrenta el manejo de las An P mexicanas. Resulta obvio que los programas de apoyo llevados a cabo en la RBM M no han tenido el éxito esperado, tanto en el sentido de su eficiencia para frenar el deterioro ambiental, como de una aceptación general de las medidas. Entre los obstáculos más sobresalientes esta la visión claramente instrumental de la política ambiental, en combinación con una marcada complejidad social: en el contexto de una situación social tradicionalmente tensa y conflictiva, las autorida- 
des federales tomaron la decisión de declarar una ANP y aplicar una normatividad ambiental recién establecida, sin consulta ni participación efectiva de los afectados; con el fin de proteger una especie excepcional en términos biológicos y, al mismo tiempo, cargada de significado político. Después de haber sido confrontada con la resistencia decidida y prolongada de gran parte de la población residente, una serie de instituciones gubernamentales y ONG diseñaron numerosos programas de apoyo económico para promover la aceptación de restricciones del acceso a y uso de los recursos forestales; defendiendo así las medidas de coerción implementadas de manera unilateral y buscando apoyo político en los ámbitos local y regional. N o obstante, no se prestó atención a la raíz del conflicto: la imposición unilateral y autoritaria de un nuevo régimen de uso múltiple-público en un espacio dominado tradicionalmente por arreglos comunales; causa última que explica la escasa aceptación de la normatividad ambiental y la limitada eficacia de las medidas de compensación. Aparte de eso, resulta problemático el hecho de que no se ha logrado todavía sobrellevar el problema de conflictos de competencia y redundancias, pese a varios intentos por establecer mecanismos de coordinación e integración intragubernamental. Ante esta realidad sociopolítica, resulta dudoso si las iniciativas más recientes para establecer un ordenamiento territorial con enfoque en la sustentabilidad ecológica serán coronadas con el éxito.

Con respecto a la creación de una plataforma de negociación multiactor, también quedan muchosobstáculos por salvar. Tomando en cuenta los requisitos para el funcionamiento eficaz de un gremio de este tipo, cabe señalar los siguientes puntos: aunque el enfoque regional del FRMM permite la participación activa de un gran número de instituciones y organizaciones heterogéneas que actúan a diferentes niveles espaciales, las facultades reales de este foro se reducen al intercambio de información y percepciones de problemas. En cambio, aún no hay evidencias que esta plataforma contribuya a una mejor coordinación de las actividades individuales. Al mismo tiempo, los problemas de organización interna del cA merman considerablemente su eficacia para influir de manera significativa en la toma de decisiones con respecto al manejo de la RBM M. Sin embargo, en ambos casos la mayor deficiencia la constituye la falta de una participación eficaz, productiva y verdaderamente representativa de las comunidades locales afectadas por las restricciones del uso tradicional de los recursos forestales. Ade- 
más, no existe ningún mediador carismático aceptado y respetado por todos los actores involucrados.

Para atender la problemática de fondo, no basta rediseñar periódicamente los programas intervencionistas u organizar eventos más frecuentados y espectaculares; es decir, recurrir a las medidas preferidas hasta la fecha, posiblemente por su bajo costo político. Lo que hace falta ante todo es un cambio de visión y de actitud. Se trata de no percibir el deterioro ambiental como un problema cuya solución corresponde a unas cuantas instituciones gubernamentales $U$ ONG, recurriendo a los instrumentos tradicionales de gobernanza, sino como resultado de un conflicto de intereses profundamente arraigado entre un grupo amplio y heterogéneo de actores con intereses y objetivos divergentes y contrapuestos, incluyendo las mismas instituciones y organizaciones protagonistas; desiguales no sólo en cuanto a las medidas de poder a su inmediata disposición, sino también al potencial de movilizar apoyo político y económico para imponer sus intereses. Frente a la realidad innegable de un campo de batalla por el aprovechamiento de los recursos naturales, conviene aceptar la legitimidad de los intereses de cada uno de los actores, incluyendo los de los más satanizados hasta la fecha, como los grupos de talamontes y los comerciantes de madera. Son precisamente estos intereses los que hay que negociar adecuadamente, tomando en cuenta los requisitos indispensables aquí expuestos. En este contexto, es importante establecer una plataforma única de negociación que será percibida por una gran mayoría de los actores como un instrumento idóneo para perseguir eficazmente sus propios intereses particulares.

Lo que se sugiere concretamente es la creación de un espacio de negociación híbrido, en el sentido que retome elementos tanto del FRM m como del CA; que combine las características y funciones de ambas instituciones, ampliando al mismo tiempo sus facultades y margen de maniobra. Por un lado, tiene que cumplir con la función de una mesa de discusión democrática y de coordinación intersectorial, establecida en el ámbito regional. Por otra parte, debe estar en condiciones de ejercer influencia inmediata en el ámbito local, es decir, fungir como un gremio con voz y voto respecto a la formulación e implementación de medidas concretas, incluyendo el alcance sectorial y territorial de los programas de apoyo; lo cual implica que parte de sus decisiones tengan validez legal directa. Por último, es indispensable institucionalizar formalmente esta plataforma y convertirla en una institución 
líder. En este contexto, resulta necesario que los actores más poderosos cedan parte de sus competencias a este nuevo gremio; lo que posiblemente provoca su resistencia. Sin embargo, esta merma de poder e influencia se podría compensar con una mayor eficacia de la política ambiental y el reconocimiento de este logro en el ámbito político-administrativo. Para asegurar una mayor congruencia entre la normatividad ambiental y la realidad social, la plataforma institucionalizada también debería fungir como interlocutor con los cuerpos legislativos de los tres niveles de gobierno, con la finalidad de proporcionar su input durante el proceso de elaboración de normas legales. O tro punto importante se refiere al establecimiento de otras formas de representación social de la población local, independiente de sus derechos agrarios. No cabe duda que se trata de un asunto delicado, pero es indispensable democratizar el mecanismo de elección de los representantes de las comunidades locales.

En fin, no cabe duda que aún quedan muchos obstáculos por salvar y tareas pendientes. No obstante, los logros parciales - pero nada despreciables- de las iniciativas pasadas dan motivos para esperar que se logre establecer una plataforma de negociación que integre más actores y que promueva una aceptación mayor de la RBM $\mathrm{m}$ y de otras AnP.

\section{Bibliografía}

Barkin, David (2000), "The Economic Impacts of Ecotourism: Conflicts and Solutions in Highland M exico," en P. M. Godde, M. F. Price y F.M . Zimmermann (eds.), Tourism and Development in Mountain Areas, CAB International, Londres, pp. 157-172.

Barkin, David (2003), "Alleviating Poverty through Ecotourism: Promises and Reality in the M onarch Butterfly Reserve of M exico", Environment, Development and Sustainability, 5, Springer N etherlands, Ámsterdam, pp. 371-382.

Blaikie, Peter (1995), "Understanding Environmental Issues", en S. M orse y M. Stocking (comps.), People and Environment, University of East Anglia, Norwich, pp. 1-30.

Blaikie, Peter (1999), "A Review of Political Ecology", Zeitschrift für Wirtschaftsgeographie, 43 (3/4), M artin-Luther Universität, $\mathrm{H}$ alle-Wittenberg, pp. 131-147. 
Brenna, Jorge E. (2006), Conflicto y democracia: la compleja configuración de un orden pluricultural, Universidad Autónoma M etropolitana, Unidad Xochimilco, M éxico.

Brenner, Ludger (2004), “Caracterización y diagnóstico sectorial para el ordenamiento ecológico de la R egión M ariposa M onarca", Instituto N acional de Ecología (informe técnico), M éxico.

Brenner, Ludger (2006), “Áreas N aturales Protegidas y Ecoturismo. El caso de la Reserva de la Biosfera M ariposa M onarca, M éxico", Relaciones, 105, El Colegio de Michoacán, Zamora, pp. 237-265.

Brenner, Ludger y H ubert J ob (2006), "Actor-O riented M anagement of Protected Areas and ecotourism in M exico", Journal of Latin American Geography, 5 (2), Syracuse University, Syracuse, pp. 7-27.

Brenner, Ludger, Julius Arnegger y $\mathrm{H}$ ubert Job, “M anagement of $\mathrm{N}$ ature-Based Tourism in Protected Areas (The Case of the Sian Ka'an Biosphere Reserve, M exico)", en A. D Ramos y P. S. Jiménez, Tourism Deveolpment: Economics and $\mathrm{M}$ anagement, $\mathrm{N}$ ova Science Publishers, $\mathrm{H}$ auppage (en prensa).

Brenner, L udger y $\mathrm{H}$ elen $\mathrm{H}$ üttl, "Actores sociales y manejo de áreas naturales protegidas. El ejemplo de la Reserva de Biosfera Sian Ka'an, Quintana Roo", Revista M exicana del Caribe, Universidad de Quintana Roo, Chetumal (en prensa).

Brower, Lincoln P., Guillermo Castilleja, Armando Peralta, José López-Gracia, Luis Bojorquez-Tapia, Salomon Díaz, Daniela M elgarejo y M onica M issrie (2002), "Q uantitative Changes in Forest Quality in a Principal Overwintering Area of the M onarch Butterfly in M exico, 1971-1999", Conservation Biology, 16 (2), Wiley, San Francisco, pp. 346-359.

Bryant, Raymond L. (1992), "Political Ecology. An Emerging Research Agenda in Third-World Studies", Political Geography, 11(1), Elsevier, Ámsterdam, pp. 12-36. 
Bryant, Raymond L. (1997), "Beyond the Impasse: the Power of Political Ecology in Third World Environmental Research", Area, 29 (1), Wiley, San Francisco, pp. 5-19.

Bryant, Raymond L. y Sinéad Bailey (1997), Third World Political Ecology, Routledge, Londres.

Chapela, Gonzalo y David Barkin (1995), M onarcas y campesinos. Estrategia de desarrollo sustentable en el oriente de Michoacán, Centro de Ecología y Desarrollo, M éxico.

Cohan, Stephanie (2007), “La organización social del turismo en la Reserva de la Biosfera M ariposa M onarca. El caso de los ejidos El Rosario y Cerro Prieto, M ichoacán", Universidad N acional Autónoma de M éxico, tesis de maestría, inédita.

Conanp (Comisión Nacional de Áreas N aturales Protegidas) (2001), Programa de manejo Reserva de la Biosfera Mariposa Monarca, Conanp, M éxico.

Conapo (Consejo Nacional de Población) (2000), Población, medio ambiente y desarrollo sustentable. Dos estudios de caso: regiones Mariposa Monarca y Costa Chica de Guerrero, Conapo, M éxico.

Galindo, Carlos, Eduardo Rendón y Adriana Quintana (2004), "La monarca de las migraciones", Pronatura, 8, Pronatura M éxico A.C., M éxico, pp. 38-45.

Galindo, Carlos y Eduardo Rendón (2005), Danaidas: Las maravillosas mariposas monarca, Fundación Telcel-wwF, M éxico.

Garibay, Claudio y Gerado Bocco (2000), Legislación ambiental, áreas protegidas y manejo de recursos en zonas indígenas forestales, El Colegio de M ichoacán, Zamora.

Goodhand, Jonathan y David Hulme (1999), "From Wars to Complex Political Emergencies: Understanding Conflict and Peace Building in the New World Disorder", Third World Q uarterly, 20 (1), Tayler \& Francis, Londres, pp. 13-26. 
Grimble, R. M , K. Chan, J. Aglionby y J. Quan (1995), Trees and Trade-offs: a Stakeholder Approach to Natural Resource M anagement, International Institute for Economic Development, Londres.

$\mathrm{H}$ ardin, Garrett (1968), "The Tragedy of the Commons", Science, 162, American Association for the Advancement of Science, Washington, D.C., pp. 1243-1248.

H arner, J ohn (2002), “M uebles Rústicos in M exico and The United States", The Geographical Review, 92 (3), American Geographical Society, N ew York, pp. 354-371.

H oth, Jürgen et al. (1999), Reunión de América del N orte sobre la Mariposa Monarca, 1997, Comisión para la Cooperación Ambiental, M ontreal.

Lambin, E. F. et al. (1999), Implementation Strategy for Land Use and Cover Change, IGBP Report 48, Estocolmo-Bonn.

Leeuwis, Cees y Anne van den Ban (2004), Communication for Rural Innovation. Rethinking Agricultural Extension, Blackwell Publishing, Oxford.

M aarleveld, M arleen y C onstant D angbégnon (1999) “M anaging N atural Resources: a Social Learning Perspective", Agriculture and Human Values, 16, Springer $N$ etherlands, Ámsterdam, pp. 267-280.

M artín, Aarón (2001), Procesos de lucha y arregl os institucionales. El manejo forestal en la Reserva de la Biosfera M ariposa Monarca, Colegio de M ichoacán, Zamora.

M elo, Carlos (2002), Áreas N aturales Protegidas en México en el siglo xx, Universidad N acional Autónoma de M éxico, M éxico.

M erino, Leticia et al. (1995), La Reserva Especial de la Mariposa Monarca: problemática y perspectivas, El Colegio de M éxico, M éxico.

M erino, Leticia y M ariana Hernández (2004), “Destrucción de instituciones comunitarias y deterioro de los bosques en la 
Reserva de la Biosfera M ariposa M onarca, M ichoacán, M éxico", Revista M exicana de Sociología, 66 (2), Universidad N acional Autónoma de M éxico, M éxico, pp. 261-309.

Ramírez, Isabel, Joaquín Giménez de Azcárate y Laura Luna (2003), "Effects of H uman Activities on M onarch Butterfly $\mathrm{H}$ abitat in Protected M ountain Forests, M exico", The Forestry Chronicle, 79 (2), Canadian Institute of Forestry, M attawa, pp. 242-246.

Rendón, Eduardo et al. (1997), “Diagnóstico social y biológico en el Reserva de la Biosfera M ariposa M onarca", Instituto $\mathrm{N}$ acional de Ecología-Dirección R eserva de la Biosfera $M$ ariposa $M$ onarca, Zitácuaro, $M$ ich., inédito.

Rendón, Eduardo (2005), Memorias de Primer Foro Regional Mariposa Monarca, wwF-Fundación Telcel, M éxico.

Semarnat (Secretaría de M edio Ambiente y Recursos $\mathrm{N}$ aturales) (2006), Manual del Proceso de O rdenamiento Ecológico, Semarnat, M éxico.

Steins, N orbert A. y Veit M . Edwards (1997), "Platforms for C ollective Action in M ultiple-Use Common Pool Resources", ponencia presentada en el congreso $\mathrm{M}$ ultiple-Use Common Pool Resources, Collective Action and Platforms for Resource Use N egotiation, Utrecht, 11 de mayo.

Tischler, Sergio y Gerardo Carnero (2001), Conflicto, violencia y teoría social: una agenda sociológica, Universidad Iberoamericana-Benemérita Universidad Autónoma de Puebla, M éxico.

Tucker, Catherine M. (2004), "Community Institutions and Forest $M$ anagement in M exico's $M$ onarch Butterfly Reserve", Society and Natural Resources, 17, Taylor \& Francis, Londres, pp. 568-587.

Van der M eer, Sjoerd (2007), "The Butterfly Effect: Butterflies, forest conservation and conflicts in the M onarch Butterfly Reserve (M exico)", tesis de maestría, Universidad de Wageningen, Wageningen, Países Bajos. 
Van Woerkum, Cees (1997), Communicatie en interactieve beleidsvorming, Bohn Stafleu van Loghum, H outen, Países Bajos.

Weizenegger, Sabine (2003), Akteursorientiertes G rossschutzgebietsmanagement - Beispiele aus Afrika südlich der Sahara, M ünchener Studien zur Sozial und Wirtschaftsgeographie, M unich.

wwF (World Wide Fund for N ature) (2004), La tala ilegal y sus impactos en la Reserva de Biosfera Mariposa Monarca, www.wwf.org.mx, febrero de 2006.

Recibido: 21 de julio de 2008. Reenviado: 10 de noviembre de 2008. Aceptado: 3 de diciembre de 2008.

Ludger Brenner. Es doctor en geografía por la Universidad de Tréveris, Alemania. Realizó una estancia posdoctoral en el Instituto de Geografía de la Universidad Nacional Autónoma de M éxico; fue coordinador el Centro de Estudios de Geografía H umana de EI Colegio de M ichoacán y actualmente es profesorinvestigador titular en el Departamento de Sociología de la Universidad Autónoma M etropolitana, Unidad Iztapalapa. Forma parte del Sistema Nacional de Investigadores. Sus líneas de investigación incluyen la geografía de turismo y el manejo de áreas naturales protegidas. 